\title{
Obesity in Adolescents: A Study on Knowledge Attitude and Practice of Teachers
}

Dr. Sunanda Jha ${ }^{1}$, Dr. Naghma Mobin ${ }^{2}$, Dr. Umashanker Prasad Keshri ${ }^{3 *}$

${ }^{1}$ Associate Professor, Department of Paediatrics, Rajendra Institute of Medical Sciences (RIMS), Rims Cir, Indraprasth Colony, Bariatu, Ranchi, Jharkhand 834009, India

${ }^{2}$ Junior Resident Academic, Department of Pediatrics, Rajendra Institute of Medical Sciences, Ranchi, Jharkhand, India

${ }^{3}$ Professor, Department of Pharmacology, Rajendra Institute of Medical Sciences (RIMS), Rims Cir, Indraprasth Colony, Bariatu, Ranchi, Jharkhand 834009 , India

DOI: $10.36347 / \mathrm{sajb} .2020 . \mathrm{v08i06.006}$

| Received: 04.06.2020 | Accepted: 16.06.2020 | Published: 21.06.2020

*Corresponding author: Dr. Umashanker Prasad Keshri

Abstract

Original Research Article

Objectives of this work is the study the prevalence of unhealthy behaviours in relation to the BMI status of students in a private school in Ranchi. A private coeducational school located in Ranchi was selected for the study. Data for predictors of obesity was collected from 325 students belonging to standard $6^{\text {th }}, 7^{\text {th }} \& 8^{\text {th }}$. A pretested questionnaire adapted from WHO's Global School Health Survey Questionnaire was used. Using anthropometric measurements of the subjects, BMI was calculated and subjects were classified as per their nutritional status. Survey of the existing canteens services was done; and knowledge, attitude \& practices of teachers regarding health, dietary and lifestyle behaviours were evaluated using a pretested questionnaire. Both undernutrition (28.0\%) and overnutrition (20.9\%) existed in the adolescents under study. Subjects showed high prevalence of unhealthy behaviours: high consumption of sweetened beverages (19.1\%), frequent consumption of outside food (41.5\%), low fruit and vegetable intake (49.5\%), physical inactivity (46.8\%), excessive TV viewing or playing computer games $(41.5 \%)$. A total of $32.9 \%$ of subjects were "at risk" i.e. had $>3$ unhealthy behaviours out of which $29.2 \%$ were underweight or normal and $47.1 \%$ were overweight or obese. Strong health and nutrition related policies and health promotion programs are very important to encourage an adolescent to adopt a healthy behaviour and to prevent under nutrition and obesity. There is an urgent need to sensitize school authorities and teachers as well as parents regarding healthy food practices and physical activity by students.

Keywords: BMI, obesity, sweetened beverages.

Copyright @ 2020: This is an open-access article distributed under the terms of the Creative Commons Attribution license which permits unrestricted use, distribution, and reproduction in any medium for non-commercial use (NonCommercial, or CC-BY-NC) provided the original author and source are credited

\section{INTRODUCTION}

Obesity is the most prevalent form of malnutrition. Obesity among adolescent age group is not only a serious concern in developed countries across the globe but it has also become a burning issue in developed countries. Overweight \& obesity are the fifth leading risk of global deaths. Once considered a high income country problem, overweight and obesity are now emerging in urban settings of low and middle income countries. There is a close association between obesity and premature death from diabetes, hypertension \& cardiovascular disease. Among Indian children prevalence is around $20 \%$, posing significant risk of lifestyle in future [1].

Changes in dietary intake, lifestyle changes and physical inactivity have resulted in obesity epidemic in developing countries. It is possible that successful prevention and treatment of obesity at this age can reduce adult incidence of cardiovascular disease [2]. Different criteria have been used to define obesity. Body mass index cut offs are most frequently used. It is calculated by formula, $\mathrm{BMI}=\mathrm{Wt}(\mathrm{kg}) / \mathrm{Ht}\left(\mathrm{m}^{2}\right)$. Children with $\mathrm{BMI}>85^{\text {th }}$ percentile for age $\left(25 \mathrm{~kg} / \mathrm{m}^{2}\right)$ are considered overweight while those $>95^{\text {th }}$ percentile for age $\left(30 \mathrm{~kg} / \mathrm{m}^{2}\right)$ are obese [3].

\section{MATERIAL AND METHODS}

A private co-educational school located in Ranchi was selected for the study after obtaining permission from school authorities. Data for predictors of obesity and anthropometry was collected from a total of 325 students belonging to standard $6^{\text {th }}, 7^{\text {th }} \& 8^{\text {th }}(10-15$ year of age) after taking informed consent from the students and parents. General information regarding awareness on health and nutrition topics, prevalence of modifiable predictors of obesity i.e. risk factors as well as willingness to adopt healthy behaviours was collected from 325 children using a pretested questionnaire 
Sunanda Jha et al., Sch Acad J Biosci, June., 2020; 8(6): 168-170

adapted from WHO's Global School Health Survey Questionnaire $^{3}$. Anthropometric measurements (height and weight) of the subjects were recorded. Using anthropometric data, BMI was calculated and subjects were classified as per there nutritional status based on WHO 2007 growth reference standards ${ }^{4}$. Subjects exhibiting $>3$ risk factors were classified as being 'at risk'.
Survey of existing canteen services was done to find out about type of food available to students and consumption trends using pretested standardized questionnaire. For evaluation of knowledge, attitude and practices (KAP) of teachers regarding healthy dietary \& lifestyle behaviours, structured, pretested questionnaire was used. Percent responses were calculated for the numerical data.

\section{RESULTS}

Table: Prevalence of unhealthy behaviours across BMI status of participants

\begin{tabular}{|l|l|l|l|}
\hline Unhealthy behaviour & $\begin{array}{l}\text { Underweight + Normal } \\
(\mathbf{n = 2 5 7})(\mathbf{\%})\end{array}$ & $\begin{array}{l}\text { Overweight + Obese } \\
(\mathbf{n = 6 8})(\mathbf{\%})\end{array}$ & Total \\
\hline $\begin{array}{l}\text { High consumption of sweetened beverages } \\
(\geq 2 \text { days/week) }\end{array}$ & $42(16.3)$ & $20(29.4)$ & $62(19.1)$ \\
\hline High frequency of eating out $(\geq 2$ days/week) & $100(38.9)$ & $35(51.5)$ & $135(41.5)$ \\
\hline Low fruits and vegetable intake $(<400 \mathrm{gm} /$ day) & $122(47.5)$ & $39(57.4)$ & $161(49.5)$ \\
\hline Physical inactivity $(\leq 3$ days/week) & $117(45.5)$ & $35(51.5)$ & $152(46.8)$ \\
\hline $\begin{array}{l}\text { Excessive TV viewing or playing computer } \\
\text { games }(\geq 120 \mathrm{~min} / \text { day })\end{array}$ & $104(40.5)$ & $31(45.6)$ & $135(41.5)$ \\
\hline "At Risk" subjects $(>3$ unhealthy behaviours) & $75(29.2)$ & $32(47.1)$ & $107(32.9)$ \\
\hline
\end{tabular}

\section{DISCUSSION}

Out of 325 adolescents under study, 211 were boys \& 114 were girls. Both undernutrition (28.0\%) and overnutrition $(20.9 \%)$ existed in the adolescents under study. Prevalence of underweight was higher in girls $(32.5 \%)$ as compared to boys $(25.6 \%)$ while a higher percentage of boys $(27.5 \%)$ were overweight and obese as compared to girls (8.8\%). Study subjects showed alarmingly high prevalence of unhealthy behaviours: high consumption of sweetened beverages (19.1\%), frequent consumption of outside foods (41.5\%), low fruit and vegetables intake $(49.5 \%)$, physical inactivity $(46.8 \%)$ and spending an unhealthy amount of time in sedentary activities like watching television and playing computer games $(41.5 \%)$. Subjects who had at least 3 unhealthy behaviours were identified as being 'at risk'. $47.1 \%$ of obese and $29.2 \%$ of underweight and normal subjects were falling in "at risk" category. Nearly $45 \%$ children brought packed lunch from home. Out of all the subjects who reported bringing lunch from home, less than $5 \%$ brought fruits while more than $20 \%$ subjects reported bringing snack items as packed lunch. On studying the perceptions of the study subjects, it was found that a majority of them (53.8\%) correctly perceived their BMI status and higher percentage of overweight and obese subjects (73.5\%) did so as compared to non-overweight $(48.6 \%)$. Similar trend was observed when perceptions regarding importance of healthy weight, benefits of physical activity and harmful effects of excessive TV watching/playing computer games were studied [4].

The school canteen when evaluated, primarily offered precooked and pre packed snacks which were high in trans fats and sugar, and carbonated soft drinks.
Knowledge attitude and practice (KAP) of teachers pertaining to 'healthy diet' was found to be inappropriate because their main concern was effect of these behaviours on scholastic performance of children with no thought about health consequence [6].

Normal weight children constituted only half of the study population indicating widespread malnutrition. There was co-existence of underweight and overweight (including obesity). While $28 \%$ of the population suffered from undernutrition, $20.9 \%$ of the study subjects were overweight ad obese. Unhealthy behaviours were prominent in the over nourished segment of the population than underweight subjects. Consumption of unhealthy, high calorie foods and beverages as corroborated by the sales trend data from the school canteen resulted in obesity as also reported in previous studies [5].

\section{CONCLUSION}

Strong health and nutrition related policies and health promotion programs are very important to encourage an adolescent to adopt a healthy behaviour and to prevent undernutrition and obesity. There is an urgent need to sensitize school authorities and teachers as well as parents regarding healthy food practices and physical activity by students.

\section{REFERENCES}

1. Parthasarathy A, Gupta P, Agrawal R, Menon PSN, Nair MKC, Sukumaran TU. IAP Textbook of Pediatrics. $5^{\text {th }}$ ed Gwalior: Jaypee Brothers Medical Publishers; 2013. 
2. Freedman DS, Dietz WH, Srinivasan SR, Berenson GS. The relation of overweight to cardiovascular risk factors among children and adolescents: the Bogalusa Heart Study. Pediatrics. 1999; 103(6):1175-82.

3. World Health Organisation (WHO) Global School-based Student Health (GSHS) Core Questionnaire Module. Available at: http://who.int/chp/gshs/GSHS_Core_Modules pdf Accessed on August 152010.

4. World Health Organisation (WHO) Technical Report Series World Health Organisation (WHO).
BMI-for-age Growth Reference Standards (5-19 years) available at: http://www.who.int/growthref/who2007_bmi_for age/en/index.html. Accessed on August 15,2010.

5. Ludwig DS, Sed KEP, Gortmaker SL. Relation between consumption of sugar sweetened drinks and childhood obesity: a prospective, observational analysis. 2001;357(9255):505-508

6. Park's Textbook of Preventive \& Social Medicine, $24^{\text {th }}$ edition. 